\title{
PLC Based Automatic Intelligent Car Parking System
}

\author{
F. Islam, M. Adil, and S. A. Alvi
}

\begin{abstract}
The main purpose of this paper was to design and implement an intelligent car parking system. The proposed system works on three modes such as ON, OFF and EMERGENCY.

The system developed is able to sense the presence of the vehicles standing at the main car parking gate through an IR sensor. These IR sensors give their output to the PLC (programmable logic controller).

Due to lack of parking spaces and skilled labour, there is a global shift towards the automatic car parking system to calculate accurate space available for car and revenue collection as a parking fee.

This new scheme provides an improvement and reliability in the current car parking system and this system can be implemented easily because it is very economical as it uses solar panel for its power consumption and also the cheap IR sensor reduces the implementation cost.
\end{abstract}

Index Terms - IR sensors, LDR (light dependant resistor), PLC (programmable logic controller), solar panel.

\section{INTRODUCTION}

Car parking systems have been around almost since the time cars were invented. In any area where there is a significant amount of traffic, there are car parking systems. Car Parking systems were developed in the early 20th century in response to the need for storage space for vehicles.

With the rapid proliferation of vehicle availability and usage in recent years, finding a vacant car parking space has become more and more difficult, resulting in a number of practical conflicts. Parking problems are becoming ubiquitous and ever growing at an alarming rate in every major city. Wide usage of wireless technologies with the recent advances in wireless applications for parking manifests that digital data dissemination could be the key to solve emerging parking problems [1].

There are several advantages of employing a car park system for urban planners, business owners and vehicle drivers. They offer convenience for vehicle users and efficient usage of space for urban-based companies. Automated car park systems save time, money, space and simplify the often tedious task of parking.

There are two types of car parking systems: traditional and automated. In the long term, automated car parking systems are likely to be more cost effective when compared to traditional parking garages. Automatic multi-storey automated car park systems are less expensive per parking slot, since they tend to require less building volume and less

Manuscript received December 5, 2014; revised November 7, 2015.

Faraz Islam, Mohammad Adil, and Sayeed Akhtar Alvi are with Aligarh Muslim University, India (e-mail: fislam2010@gmail.com). ground area than a conventional facility with the same capacity. Both automated car parking systems and automated parking garage systems reduce pollution as cars are not running or circling around while drivers look for parking spaces.

Quickly finding a vacant space in a multilevel parking lot is difficult if not impossible, especially on weekends or public holidays. Finding spaces during weekends or public holidays can take more than 10 minutes for about $66 \%$ of visitors. Stadiums or shopping malls are crowded at peak periods, and difficulty in finding vacant slots at these places is a major problem for customers. Insufficient car park spaces lead to traffic congestion and driver frustration. If a car is parked in such a way that it occupies two parking slots rather than one, this is called improper parking. Improper parking can happen when a driver is not careful about another driver's rights [2]. Problem faced by people due to lack to car parking management is shown in Fig. 1.

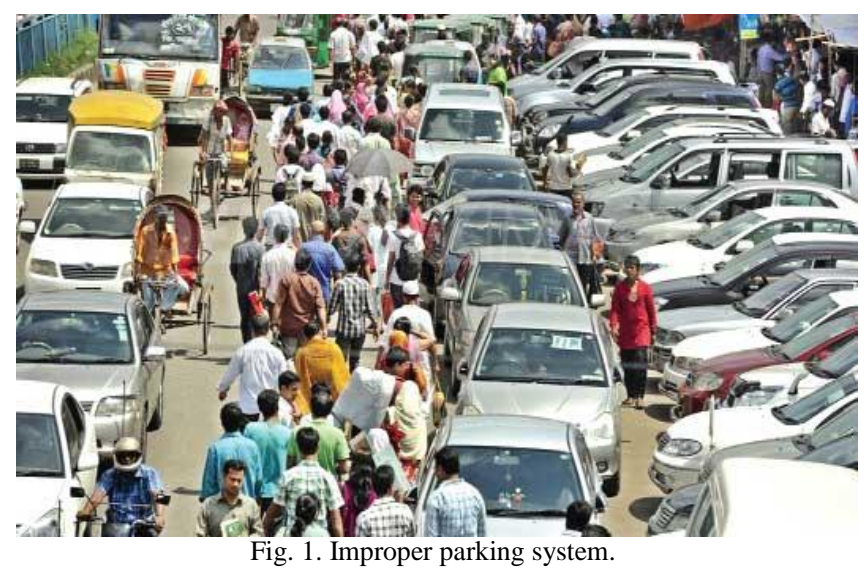

To solve these entire problems we came to a conclusion of having an automatic intelligent car parking system that ensures the safety of the driver as well as saves time and parking spaces.

Some of the benefits of automatic intelligent car parking system are, it can accommodate maximum number of cars in minimum spaces, customized parking solutions, low maintenance and operation cost, safety for both car and the driver, faster parking and retrieval and eco-friendliness.

\section{OBJECTIVE}

To develop an Automatic Intelligent Car Parking System based on PLC using IR sensors, Light Dependant Resistor (LDR) and solar panels for power consumptions.

The Automatic Intelligent Car Parking System simply uses the input module from IR Sensors and LDRs to provide it to the Programmable Logic Controller (PLC) to ensure easy, reliable and effective car parking management. 


\section{Methodology}

The automatic intelligent car parking system is a smart system which uses a set of LDRs and IR sensors to ensure effective and safe car parking management. The intelligent car parking system works in three modes such as $\mathrm{ON}$, OFF and EMERGENCY.

The ON mode gets activated at the day time when the use of car parking system is at its peak. The OFF mode is used at night when there is least use of car parking system. The EMERGENCY system gets activated whenever the parking authority staff presses the emergency push button when something unlawful happens. In emergency mode the PLC directs to close all the gates and no car is allowed to enter or leave the car parking.

At the car parking ground we have a space for six cars and six LDRs are place on each car space to detect the presence of a car over it. If six cars are parked at the parking then the LDR sends this output to PLC.

One set of IR sensor is placed at the main gate of the car parking which detects the presence of a car waiting to enter the car parking. If the IR sensor detects the presence of a car, then the output is send to the PLC.

The PLC manipulates the data provided to it by the LDR and the IR sensor to ensure whether a car can be parked or not. If the data provided by the LDR shows the possibility of available space for car parking and also the IR sensor detects the presence of car waiting to get parked, then the PLC directs the main parking gate to open and allow the car to enter the parking area.

If the data provided by the LDR shows the possibility of fully occupied parking space, then the PLC stops the main gate from opening and directs the car to next parking ground. The Simulation image of the car parking system is shown in Fig. 2.

The whole parking system is very economical and feasible as it uses the solar panel for its power consumption. Intelligent car parking system uses a series of batteries that are charged by the solar panel using the solar radiations from the sun. The solar panel system is place at the unused vacant space in the parking premises where it uses the sun's radiation and converts it into DC power and stores in heavy battery. The heavy battery can provide power backup for a longer period depending upon how frequently a car enters the parking system [3].

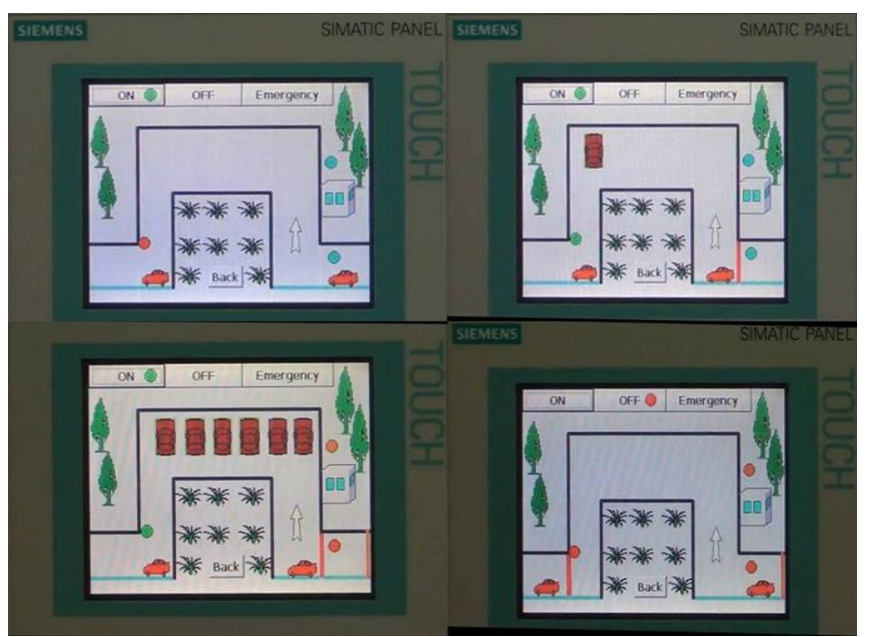

Fig. 2. Simulation of intelligent car parking system.

\section{PROCESS DESCRIPTION}

The chapter gives a detailed explanation of the various processes taking place in Automatic Intelligent Car Parking system. The automatic intelligent car parking system's operations are shown in Fig. 3.

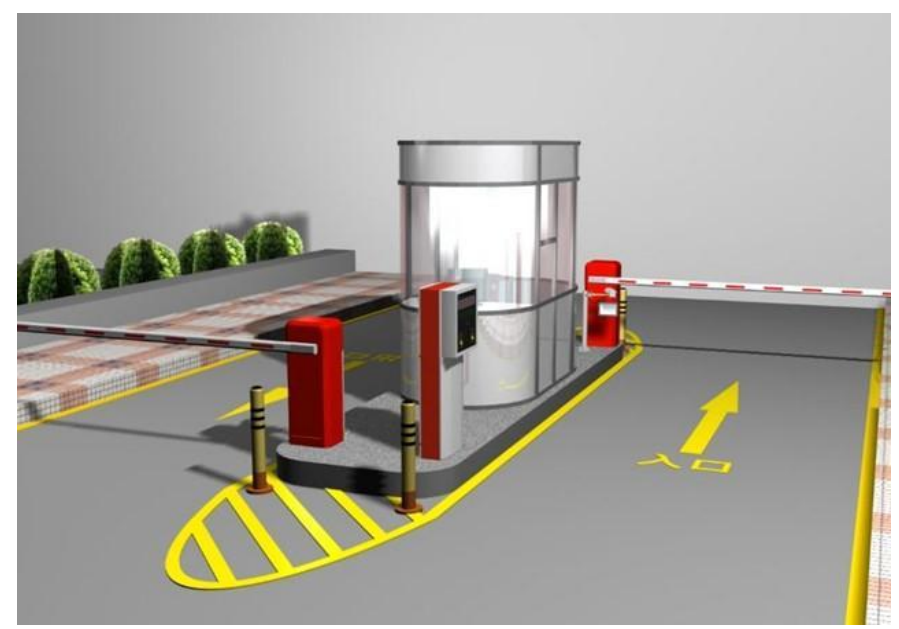

Fig. 3. Automatic Intelligent Car Parking System.

\section{A. Block Diagram}

The block diagram of the automatic intelligent car parking system is shown in Fig. 4. The diagram shows the input and output components connected to PLC.

The input component comprise of six LDR sensors, IR sensors and a security camera. The output components comprise of entry gate and exit gate mechanism. The input, output and the PLC are connected to the batteries that are charged with the help of solar panel.

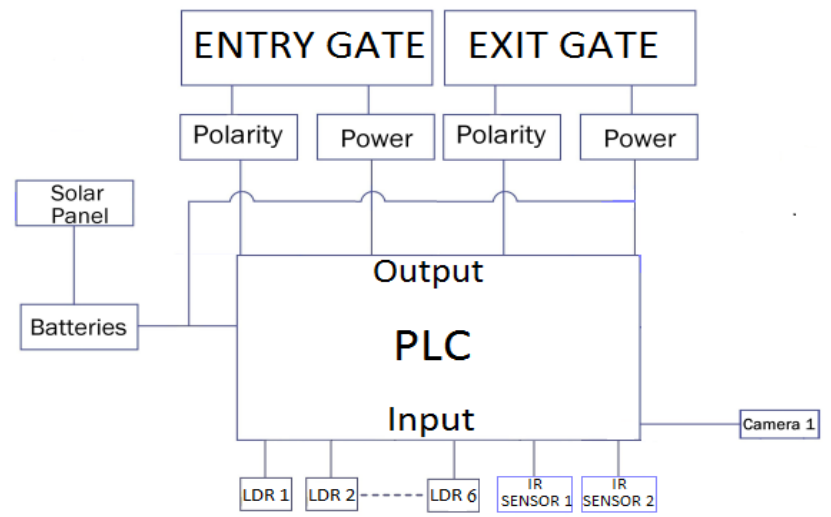

Fig. 4. Block diagram.

\section{B. Input Module}

The input module of the automatic intelligent car parking system includes the IR sensors, LDRs, Camera and Push button Switch. There are two sets of IR sensor. First IR sensor is placed at the entry gate to detect the presence of the vehicle at the entry gate. Second IR sensor is placed at the exit gate which helps in detecting the vehicle at the exit gate and directs the PLC to open the gate.

There are six LDR sensors placed on each of the car parking ground of the automatic intelligent car parking system. The LDR detects the presence of the vehicle over it and helps in calculating the exact number of spaces available in a particular parking ground whose output is 
given to the PLC.

Push button switch stands for security measurements. The push button switch is used whenever an emergency situation occurs. If the security guard finds something unusual or suspicious through the security cameras then he pushes the push button switch to enable security mode of the parking system. The push button enables the security alarm and directs the PLC to shut down all the gates of the car parking system.

\section{Output Module}

The output module of the automatic intelligent car parking system consists of entry gate and exit gate mechanism. These mechanisms are attached with the batteries that are charge by the solar panel.

The opening and closing of the gate depends upon the IR sensors output. Entry gate opens whenever the IR sensor detects a vehicle at the entry gate and a space is available for parking. The exit gate opens whenever the IR sensor detects the presence of a vehicle at the exit gate and also when the emergency mode is inactive.

\section{Signal Processing}

The input voltage to the PLC should be $24 \mathrm{~V}$ therefore the output of the IR sensors and LDR sensors cannot be given directly to the PLC. Hence they are given through signal conditioning circuits which condition the input signals and in turn gives it as an input to the PLC. For safety purpose the inputs are not given directly to the PLC. They are given through relay circuits. The relay consists of 3 terminals common, NO and NC, this circuit is also known as Reverse Polarity Circuit and is shown in (Fig. 5). The $24 \mathrm{~V}$ which is to be pulled into the PLC will be available in the common terminal [4]. Hence depending upon the necessary signals the circuits closes or opens thereby connecting to the PLC [4].

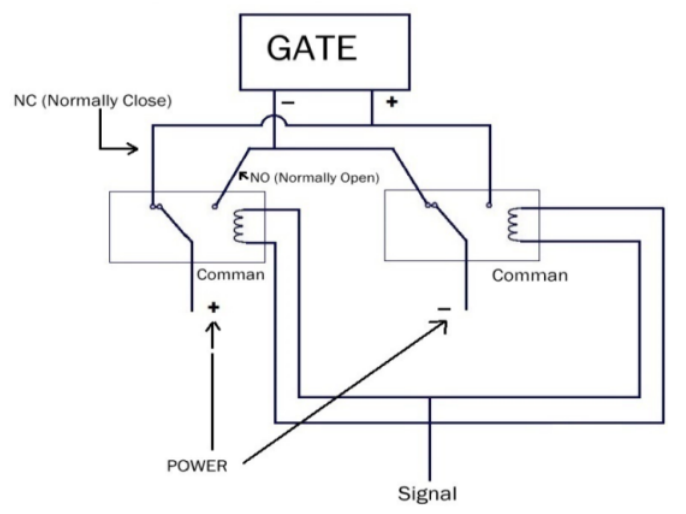

Fig. 5. Reverse polarity circuit.

\section{E. Programmable Logic Controller (PLC)}

The PLC used in is SIMATIC S7-300, CPU 316-2DP with integrated $24 \mathrm{~V}$ DC power supply, $128 \mathrm{KBYTE}$ working memory 2nd INTERF. DP-MASTER/SLAVE.

The details and information of PLC S7-300, CPU 3162DP is given in Table I [5].

A Programmable Logic Controller, PLC or Programmable Controller is a digital computer used for automation of electromechanical processes, such as control of machinery on factory assembly lines, amusement rides, or light fixtures. The PLC was designed to provide flexibility in control based programming and executing logic instruction. PLC allows for shorter installation time and faster commissioning through programming rather than wiring [4].

\begin{tabular}{|c|c|c|c|}
\hline \multicolumn{2}{|l|}{ CPU and Product Version } & \multirow{6}{*}{$\begin{array}{l}\text { S7 timers } \\
\text { - } \text { Adjustable retentivity } \\
\text { - } \text { Preset } \\
\text { - Timing range } \\
\text { IEC Timers } \\
\text { - Type }\end{array}$} & \multirow{2}{*}{$\begin{array}{l}128 \\
\text { from T } 0 \text { to } T 127\end{array}$} \\
\hline MLFB & 6ES57 316-2AG00-0AB0 & & \\
\hline - Hardware version & 01 & & No retentive times \\
\hline - Firmware version & v 1.1.0 & & $10 \mathrm{~ms}$ to $9990 \mathrm{~s}$ \\
\hline $\begin{array}{l}\text { - Matching programming } \\
\text { package }\end{array}$ & $\begin{array}{l}\text { STEP 7 V 5.0; } \\
\text { Service Pack } 03\end{array}$ & & Yes \\
\hline \multicolumn{2}{|l|}{ Memory } & & $\mathrm{SFB}$ \\
\hline Work memory & & \multicolumn{2}{|c|}{ Data areas and their retentive characteristics } \\
\hline - integral & $128 \mathrm{~KB}$ & \begin{tabular}{|l} 
Retentive data area as a \\
whole (inc. flags, timers,
\end{tabular} & 4736 bytes \\
\hline - Expandable & no & counters) & \\
\hline Load memory & & Bit memories & 2048 \\
\hline - integral & $192 \mathrm{~KB}$ & - Adjustable retentivity & MB 0 to MB 255 \\
\hline - Expandable FEPROM & Up to 4 MB & - Preset & MB 0 to MB 17 \\
\hline - Expandable RAM & no & Clock memories & 8 (1 memory byte) \\
\hline Backup & Yes & Data blocks & 511 (DB 0 reserved) \\
\hline - With battery & All data & - Size & $\max .16 \mathrm{~KB}$ \\
\hline - Without battery & 4736 bytes & - Adjustable retentivity & max. 8 DB 4096 data bytes \\
\hline \multicolumn{2}{|l|}{ Processing times } & - Preset & No retentivity \\
\hline \multicolumn{2}{|l|}{ Processing times for } & Local data (non-alterable) & max. 1536 bytes \\
\hline - Bit instructions & $0.3 \mu \mathrm{s}$ minimum & - Per priority class & 256 bytes \\
\hline - Word instructions & $1 \mu \mathrm{s}$ minimum & \multicolumn{2}{|l|}{\begin{tabular}{|l|} 
Blocks \\
\end{tabular}} \\
\hline - Double integer math & $2 \mu \mathrm{s}$ minimum & \multirow{8}{*}{$\begin{array}{l}\text { OBs } \\
\text { - } \quad \text { Size } \\
\text { Nesting depth } \\
\text { - Per priority class } \\
\text { - additional levels within } \\
\quad \text { an error OB } \\
\text { FBs } \\
\text { - Size } \\
\text { FCs } \\
\text { - Size }\end{array}$} & See Instruction List \\
\hline $\begin{array}{l}\text { - Floating-point math } \\
\text { instructions }\end{array}$ & $50 \mu \mathrm{s}$ minimum & & $\max .16 \mathrm{~KB}$ \\
\hline \multicolumn{2}{|c|}{ Timers/Counters and their retentive characteristics } & & 8 \\
\hline $\begin{array}{l}7 \text { counters } \\
-\quad \text { Adjustable retentivity }\end{array}$ & $\begin{array}{l}64 \\
\text { from C } 0 \text { to } C 63\end{array}$ & & 4 \\
\hline - Preset & from $\mathrm{CO}$ to $\mathrm{C} 7$ & & $\max .256$ \\
\hline - Counting range & 0 to 999 & & $\max .16 \mathrm{~KB}$ \\
\hline IEC Counters & Yes & & $\max .256$ \\
\hline - Type & SFB & & $\max .16 \mathrm{~KB}$ \\
\hline
\end{tabular}

A PLC is an example of a hard real time system since output results must be produced in response to input conditions within a limited time, otherwise unintended operations will result. Programs to control machine operations are typically stored in battery-backed-up or nonvolatile memory [5].

The advantages involved in PLC's are:

PLCs are more reliable and faster in operation.

They are smaller in size and more readily can be expanded.

They require less electric power.

They are less expensive compared to electromechanical relays for the same number of

Control functions.

PLCs have very few hardware failures when compared to electromechanical relays. Special functions like time delay actions and counters can be easily performed using PLCs [2].

\section{F. IR Sensors}

A typical system for detecting infrared radiation is given in the block diagram (Fig. 6).

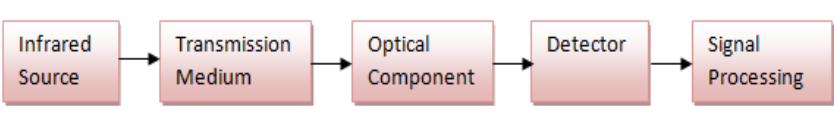

Fig. 6. IR sensor block diagram.

\section{G. Infrared Source}

All objects above $0 \mathrm{~K}$ radiate infrared energy and hence are infrared sources. Infrared sources also include blackbody radiators, tungsten lamps, silicon carbide, and various others. For active IR sensors, infrared Lasers and LEDs of 
specific IR wavelengths are used as IR sources.

\section{H. Transmission Medium}

Three main types of transmission medium used for Infrared transmission are vacuum, the atmosphere, and optical fibres. The transmission of IR - radiation is affected by presence of $\mathrm{CO}_{2}$, water vapour and other elements in the atmosphere. Choice of IR band or a specific wavelength is dictated by the technical requirements of a specific application.

\section{Optical Components}

Often optical components are required to converge or focus infrared radiations, to limit spectral response, etc. To converge / focus radiations, optical lenses made of quartz, $\mathrm{CaF}_{2}$, Ge and $\mathrm{Si}$, polyethylene Fresnel lenses, and mirrors made of $\mathrm{Al}, \mathrm{Au}$ or a similar material are used. For limiting spectral responses, band pass filters are used.

\section{J. Infrared Detectors}

Various types of detectors are used in IR sensors. Important specifications of detectors are

- Photosensitivity or Responsiveness

- Noise Equivalent Power (NEP)

NEP represents detection ability of a detector and is the amount of incident light equal to intrinsic noise level of a detector. The working of IR Sensor is shown in Fig. 7.

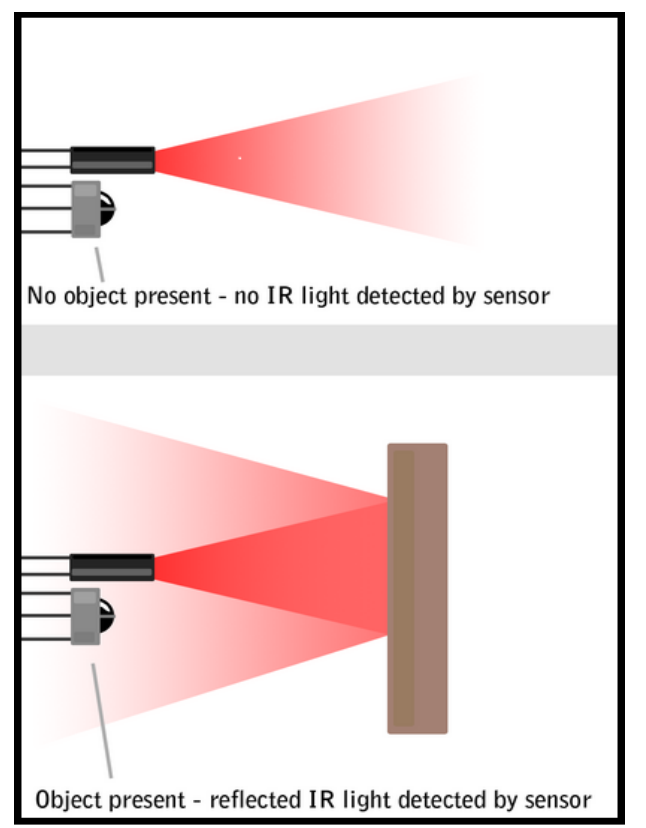

Fig. 7. Working of an IR Sensor.

In addition, wavelength region or temperature to be measured, response time, cooling mechanism, active area, no of elements, package, linearity, stability, temperature characteristics, etc. are important parameters which need attention while selecting IR detectors.

\section{K. Space Detection Using LDRs}

In automatic intelligent car parking system we have space for five cars. In order to calculate the exact number of car spaces available in the parking system, LDRs are used.

Five LDRs are placed above the parking ground and output is provided to the PLC to get the exact number of car space available in a parking ground. As a vehicle moves over the LDR, the PLC gets the information that one space has been occupied by a car and four spaces are still vacant in the parking system. When all the vacant spaces are occupied by cars then the PLC directs the car towards next car parking ground.

\section{Parking System Powered by Solar Panel}

A solar panel is a collection of solar cells. Lots of small solar cells spread over a large area can work together to provide enough power to be useful. The more light that hits a cell, the more electricity it produces. Solar panel converts the sun's radiation that is in the form of light into electricity [6].

The IR sensors and LDRs are powered by photovoltaic panels mounted on the lighting structure. The photovoltaic panels charge a heavy rechargeable battery, which provides power to the components of car parking system during the night.

System work is simple, the use of photovoltaic solar cells made of the principle effect of solar panels during the day and to receive solar radiation into electrical energy output [6].

\section{CONCLUSION}

The main objective of this paper was to develop an Intelligent Car Parking system based on public reviews and specifications. This system was successfully implemented using PLC. We considered this paper as a journey where we acquired knowledge and also gained some insight into the subject which we have shared in this report.

The Intelligent car parking system provides a unique $22^{\text {nd }}$ century automated car park system. In this system basically there are LDR (Light dependant resistor) panels powered by solar energy installed within the parking area. The automated barrier will have the required knowledge of the available space through a database directly connected with the control centre of LDR panels.

This parking system was designed in order to minimize human labour and to save the precious time of car owners waiting to find a parking spot. This system's data could be also incorporated in to an app which would let users to access information about the availability of parking spots in different locations with this system installed in them.

This system would also decrease the cost of electricity as the whole system functions on solar energy. This is a complete eco-friendly energy system. This project tout's green energy.

\section{ACKNOWLEDGMENT}

This paper is an outcome of rigorous work done under the supervision and guidance of our research guides. We would like to pay our sincere thanks to them, for their kind support and cooperation

\section{REFERENCES}

[1] M. Grwal, "Comparative implementation of automatic car parking system with least distance parking spaces in wireless sensor network," International Journal of Scientific and Research Publications, vol. 2, iss. 10, October 2012.

[2] S. Sarayu, S. S. Rajendra, and V. V. Bongale, "Design and fabrication of prototype of automated smart car parking system using 
programmable logical controllers (PLC)," International Journal of Scientific Engineering and Technology, vol. 2, iss. 9, pp. 857-860.

[3] B. H. Khan, Non-Conventional Energy Resources, 2nd ed. Tata McGraw-Hill Education, 2009, pp. 159-177.

[4] J. R. Hackworth and F. D. Hackworth, Programmable Logic Controllers: Programming Methods and Applications, 1st ed. Pearson, 2006, pp. 128-138.

[5] W. Bolton, Programmable Logic Controllers, 5th ed. Elsevier Science, 2011, pp. 112-124

[6] S. P. Sukhatme, and J. K. Nayak, Solar Energy: Principles of Thermal Collection and Storage, 3rd ed. Tata McGraw-Hill Education, 2008.

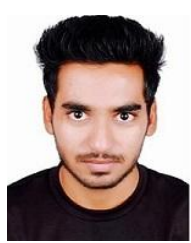

Faraz Islam was born in Varanasi, Uttar Pradesh, India on July 8, 1992. He graduated from Our Lady of Fatima and from St. Fidelis Aligarh, Uttar Pradesh, India in 2008 and 2010 respectively. Currently he is pursuing his computer engineering degree at Zakir Hussain College of Engineering and Technology, Aligarh Muslim University, Aligarh, Uttar Pradesh, India. He was offered a summer training program in Octodi Engineering India Pvt. Ltd. in September 2013. Mr. Islam holds a keen interest in research work and has published two international papers during his under-graduate degree program. He is the vice-president of Association of Computing Machinery's (ACM) student chapter in Aligarh Muslim University. He is also a founding member and Treasurer of "SOCH beyond the Imagination", an NGO that works for the welfare and upliftment of unprivileged students. He intends to continue pursuing this interest in the field of microprocessors, automation, simulation and information technology.

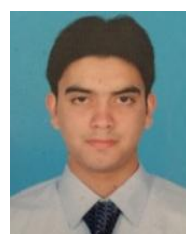

Mohammad Adil was born in a small town of Utta Pradesh, India on September 28, 1991. Mr. Adil moved to Kuwait when he was three. He completed his secondary and senior secondary education from Fahaheel Al-Watanieh Indian Private School in 2007 and 2009 respectively. $\mathrm{He}$ is currently pursuing his electronics engineering degree at Zakir Hussain College of Engineering and Technology, Aligarh Muslim University. He is the founder of India's leading shopping comparison website known as "Pullbird". His area of interest for specialization is in the field of instrumentation and control systems.

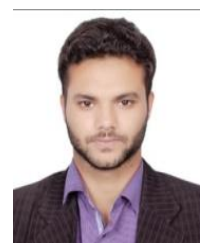

Sayeed Akhtar Alvi was born in Aligarh, Uttar Pradesh, India. $\mathrm{He}$ is pursuing the bachelor of technology in electrical engineering at Zakir Hussain College of Engineering and Technology, Aligarh Muslim University. Mr. Sayeed received his high school degree from Our Lady of Fatima and the secondary school degree from Senior Secondary School (Boys), A.M.U. in 2010 and 2012 respectively. In 2014 he completed a summer internship programme at Bharat Heavy Electricals Limited, Hyderabad. His area of training focus was on manufacturing and insulation of turbo generators by vapour pressure impregnation processes. 